\title{
BUSINESS EXPECTATIONS AND PREFERENCES REGARDING THE INTRODUCTION OF DAYLIGHT SAVING IN QUEENSLAND
}

\author{
Andrew Worthington ${ }^{*}$ \\ University of Wollongong \\ Wollongong, New South Wales
}

\begin{abstract}
This paper examines business support for the introduction of state-wide and zonal daylight saving time in Queensland on the basis of a survey of 708 businesspersons in 2002. Binary logit models are specified with the dependent variable defined as support for the introduction of daylight saving and the independent variables comprising industry and region identifiers, assessment of current and future business conditions, expectations of the impact of daylight saving on profits, sales, administration costs and staffing and the number of employees. The results suggest that support for the introduction of daylight saving is a function of positive expectations regarding staffing, sales and administration costs and is associated with the utility and communications, finance and insurance and cultural and recreational services industries. There also appears to be strong rural and regional resistance to the introduction of daylight saving, even among the business community
\end{abstract}

\section{INTRODUCTION}

Despite being first implemented in Australia more than eighty-five years ago, daylight saving remains controversial. Every October the advent of daylight saving time (DST) in Tasmania, New South Wales, Victoria, the Australian Capital Territory and South Australia brings recurrent criticism of a practice that nearly doubles the number of Australian time zones and increases by half the east-west time spread. In Queensland especially, the conflict between those in favour of aligning the state with the other eastern states, and those maintaining standard time remains largely unresolved, despite a referendum on the matter.

Like the rest of Australia, DST was first used in Queensland during WWI and WWII. DST was not adopted again in Queensland until Tasmania championed a trial season in 1971/72 that was supported by Queensland, New South Wales, Victoria, South Australia and the Australian Capital Territory. Queensland did not use DST again until 1989/90, and then only until 1991/92 when it was abandoned following a referendum [see Worthington (2003a) for a more detailed account of the origins of daylight saving and its implementation in Australia and elsewhere].

\footnotetext{
${ }^{*}$ The author would like to thank participants at the $32^{\text {nd }}$ Conference of Economists and an anonymous referee for helpful comments on an earlier version of this paper. The support of Commerce Queensland in providing the survey data is also gratefully acknowledged.
} 
Queensland's 'failure' to participate in DST alongside most other Australian states and territories has been the subject of ongoing debate. On one hand, businesses throughout Queensland have repeatedly called for the introduction of daylight saving, especially in South-East Queensland (Fortitude Valley and Districts Chamber of Commerce, 2003):

For business and those dependent on markets, the confusion caused by being on the same time as the southern states for half of the year and one hour behind for the other six months is quite costly. One-quarter to one-third of workday communication time is lost, not to mention causing confusion for customers. Travel or shipping services must adjust or reprint arrival or departure times to account for changes, and sometimes employee work shifts altogether. Other benefits of shifting South-East Queensland to daylight saving time are reduced energy, reduced crime and traffic accidents, improved flight schedules, increased sales, business development and recreational time.

These pressures for conformity are likely to continue and increase alongside the ever-growing importance of the tertiary sector in Queensland over the primary and secondary sectors, in terms of both employment and state product. And indeed, similar arguments have been made by lobbyists in Britain to abandon Greenwich Mean Time (GMT) in favour of Central European Time (GMT +2 in summer and +1 in winter) and thereby bring it in line with most other members of the European Union. On the other hand, rural and regional Queensland, as represented by agricultural lobby groups (AgForce, 2001), has consistently opposed the introduction of daylight saving:

Fortunately, the Premier is sticking to his pledge from last Saturday night to govern for all Queenslanders and has said that daylight saving would not be introduced during this term because of the negative effect on rural and regional areas...the people of Queensland decided at a referendum that they did not want daylight saving. "How many times do we have to revisit this issue?”

And even proposals for a zonal system in Queensland with daylight saving confined to the urbanised southeast has met with little enthusiasm (AgForce, 1999):

A proposal to introduce a zonal system for daylight saving could widen the divide between the Brisbane metropolitan area and regional Queensland. "It's never going to meet all the needs of businesses throughout the State and it's certainly not going to meet the needs of education and lifestyle for all our regional and rural communities”.

Putting aside the apparent politicisation of the DST debate, the clear benefit of DST is the increase in end-of-day daylight recreation and leisure time for citizens in participating jurisdictions. This varies for each person, with those most able to adapt their pattern of waking, working and leisure hours to the longer days likely to have most benefit. It also varies according to geographic location, since the marginal benefits of DST are greatest in higher latitudes where the gain in sunlight in summer over winter is more. Unfortunately, the 
recreation and leisure time benefits of DST, and presumably the main reasons for its widespread adoption, have not been quantified in Australia or elsewhere.

Apart from these household utility benefits, the purported benefits and costs of DST have concentrated on just a few, and generally minor, areas. To start with, it is argued that DST saves energy. For example, a US Department of Transport study found that adopting DST in March and April 1974/75 saved the equivalent energy of 10,000 barrels of oil per day. More recently, a simulation study of residential energy consumption in a typical US house in 224 locations by Rock (1997) found that total energy consumption in fact increased on average by 0.147 percent when summer daylight saving time was used in conjunction with winter standard time, and was only reduced slightly when daylight saving was adopted year round.

It has also been suggested (largely anecdotally) that daylight saving is associated with a fall in crime. Because more people get home from work and school and complete more activity in the daylight, their exposure to some crimes lessens, since these are more common in darkness than in light. Another possibility is that the change in photoperiod induced by daylight saving time may have an effect on sleep deprivation and/or psychiatric presentation. In a UK study, Shapiro et al. (1990) examined the incidence of parasuicide presentations, psychiatric outpatient contacts and inpatient admission, and registered suicides following the start of daylight saving and found no discernible impact, either through the change in photoperiod or the small impact on the circadian rhythm.

A more significant amount of research has been conducted into the impact of daylight saving on traffic accidents. For example, Ferguson et al. (1995) found that there were 174 fewer vehicle occupant fatalities and 727 fewer pedestrian fatalities associated with the introduction of daylight saving in the US between 1987 and 1991 and Sullivan and Flannagan (2002) used the changeover to daylight saving to conclude that pedestrians were three to nearly seven times more likely to be injured at night than in the day. Lambe and Cummings (2000) found that the sleep deprivation normally associated with the change over to daylight saving had no measurable impact on crash incidence in Sweden, though Varughese and Allen (2001) linked a small increase in fatal accidents with the Monday following the changeover in the US. In a Canadian study, Coren (1996b) also found a significant increase (some eight percent) in accident risk on the Monday following the spring change to daylight saving and a comparable decrease in the fall change from daylight saving. Studies by Green (1980), Hicks et al. (1983), Coren (1996a), Whittaker (1996) and Vincent (1998) have also examined the impact of daylight saving and/or the transition to and from daylight saving on the incidence of traffic accidents. 
Finally, in a recent provocative article, Kamstra et al. (2000; 2002) found that the average Friday-to-Monday stock return on daylight saving weekends was 200 to 500 percent larger than the average negative return for other weekends in the year (the so-called 'weekendeffect' market anomaly) and thereby associated with a one-day loss of US\$31 billion on the NYSE, AMEX and NASDAQ markets alone. Kamstra et al. (2000; 2002) linked this 'daylight saving effect' with the sleep desynchronosis associated with the change in the circadian rhythm and its (negative) impact on sleep patterns. Worthington (2003b), however, found no evidence of an equivalent daylight saving effect, at least in Australia, after taking into account the presence of outliers and adjustments for heteroskedasticity and autocorrelation suggested by Pinegar (2002).

The purpose of the present paper is to add to the small but evolving daylight saving literature the results of a survey administered to Queensland businesspersons in 2002. The survey focuses on business preferences for the adoption of daylight saving in Queensland and links these with perceptions regarding its impact on profits, sales and administration costs, amongst others. It thereby provides an important input into current economic policy regarding preferences for daylight saving in Queensland and an indication of the benefits and costs associated with its reintroduction. To the author's knowledge this is the first of its kind, both in Australia and overseas, and adds significantly to the literature concerning the economic benefits and costs of daylight saving. The remainder of the paper is organised as follows. In the first section the empirical methodology and data collection employed in the analysis is explained. The second section discusses the results. The paper ends with some brief concluding remarks in the final section.

\section{RESEARCH METHOD AND DATA}

Commerce Queensland derived the data used in this study from a survey of 708 Queensland businesspersons. A key objective was to assay not only the level of business support for the introduction of DST into Queensland as a whole (and thereby eliminate the time inconsistencies between it and the other eastern states) but also whether an alternative policy of introducing DST on a zonal basis into Brisbane (capital city) or the Gold Coast (tourist area) had support. Apart from surveying the respondents on their attitudes regarding the introduction of DST, the survey also elicited responses on the perceived impact of DST on various aspects of business operations, perceptions of current and future business conditions and the regional and industry classification of the respondents' business. The survey 
accompanied the regular quarterly information gathering process used by Commerce Queensland to identify trends and outlooks in state business conditions.

The analytical technique employed in the present study is to specify businesspersons' attitudes regarding the introduction of DST as the dependent variable $(y)$ in a regression with perceptions, business conditions and outlook, and other characteristics as explanatory variables $(x)$. The nature of the dependent variable (either support or reject the introduction of DST) indicates discrete dependent variable techniques are appropriate. Accordingly, the following binary logit model is specified:

$$
\operatorname{Prob}(y=1)=\frac{1}{1+e^{-\beta^{\prime} x}}
$$

where $x$ comprises a set of characteristics posited to influence the decision to support or reject the introduction of DST, $\beta$ is a set of parameters to be estimated and $e$ is the exponential. The coefficients imputed by the binary logit model provide inferences about the effects of the explanatory variables on the probability of supporting DST.

The dataset employed is composed of four sets of information. The first set of information relates to preferences regarding the introduction of DST and comprises the dependent variable in the binary logit model in Equation (1). In the survey, the respondents were asked their opinion regarding the introduction of DST into Queensland as a whole and into the Brisbane or Gold Coast regions alone. Respondents' responses are thus categorised into three separate binary variables as either: (i) those who do not support the introduction of DST in Queensland or Brisbane alone or the Gold Coast alone $(y=0)$; and (ii) those who support the introduction of DST in Queensland (DSQ) or Brisbane alone (DSB) or the Gold Coast alone (DSG) $(y=$ 1). These comprise the dependent variables in three separate analyses aimed at explaining support for the introduction of DST. Selected descriptive statistics are provided in Table 1. Overall, 426 respondents (60.2 percent) supported the introduction of DST into Queensland as a whole, 184 (26.0 percent) would support the introduction of DST into Brisbane alone, and 188 (26.6 percent) would support its introduction into the Gold Coast alone.

\section{$<$ TABLE 1 HERE $>$}

The next three sets of information are specified as explanatory variables. The first of these relates to organisational characteristics obtained by the survey. The first two variables relate to each businessperson's assessment of current $(B S T)$ and future $(B S F)$ business conditions as defined on a five-point scale $(+1$ to +5$)$ categorised from very poor to very satisfactory. As a rule, it could be expected that current and expected future business conditions play some role 
in how a specific policy change is received. However, it is not known what influence the various perceptions of business conditions will have on whether the introduction of DST is supported. For example, business conditions currently and in the future may be seen as fairly satisfactory, though whether this encourages businesspeople to support the introduction of daylight saving will depend on the interaction with each person's assessment of the impact of daylight saving on these conditions now and in the future. Accordingly, no particular a priori sign is hypothesised when support for the introduction of DST is regressed against $B S T$ and $B S F$.

The next four variables in the set of organisational characteristics are derived from perceptions of the potential impact of the introduction of DST. Responses concerning staffing $(S T F)$, sales $(S A L)$, administration/paperwork $(A D M)$ and profits $(P R F)$ are scored on a ninepoint scale $(-4$ to +4$)$ categorised from very strong negative to very strong positive. The internal reliability for these four variables is 0.925 suggesting a high degree of consistency between the various measures of the positive and negative outcomes associated with the introduction of DST. Once again, perceptions regarding the impact of DST will depend on both the interactions between the benefits and costs of aligning Queensland or the regions with the other eastern state time zones, and the benefits and costs of DST itself and its impact on these four dimensions of business operations.

Generally, positive perceptions of DST increasing sales and profits and lowering staffing and administration/paperwork requirements are expected to increase the likelihood a given respondent will support the introduction of DST in some form or another. Positive coefficients are hypothesised when support for the introduction of DST (whether DSQ, DSB or $D S G$ ) is regressed against $S T F, S A L, A D M$ and $P R F$. The final variable in the set of organisational characteristics is the number of employees $(E M P)$ in each respondent's organisation. The main hypothesis here is that larger organisations may have the scale economies necessary to cope with both the transition to and from DST and a positive coefficient is expected when support for the introduction of DST (whether DSQ, DSB or $D S G)$ is regressed on $E M P$.

The next set of explanatory variables is twelve dummy variables reflecting each respondent's industrial classification: namely mining $(M N G)$, manufacturing $(M F G)$, electricity, gas, water and communications $(E W C)$, construction $(C O N)$, wholesale trade $(W T R)$, retail trade $(R T R)$, accommodation, cafes and restaurants $(A C R)$, transport $(T R N)$, finance and insurance $(F I N)$, property and business services $(P R P)$, government services $(G O V)$ and cultural and recreational services $(C U L)$. The control group for the industry 
dummy variables is agriculture, forestry and fishing. It is thought that support for the introduction of DST amongst the business community is closely aligned with the industry in which they operate, and some differences in preferences may arise other than that reflected in STF, SAL, ADM and PRF above.

For example, one potential outcome of DST is the substitution from indoor to outdoor leisure activities. This could be expected to have a positive impact on businesses like cafes, restaurants and other recreational activities and these industries could be expected to support DST. As an alternative, the negative impact associated with the introduction of DST is thought mainly to relate to industries where problems are associated with work practices adjusting from true solar or standard time. Industries that rely on outside activities such as agriculture, forestry and fishing, mining and construction may then not support DST. Finally, several industries are thought to favour the introduction of DST in Queensland because of the negative impact from the lack of conformity with the other eastern states and the reduction of common work hours with the current system. The finance and insurance, transport and storage and communications industries are usually regarded as supporting DST for this reason. The ex ante sign on $M N G, M F G, E W C, C O N, W T R, R T R, A C R, T R N, F I N, P R P, G O V$ and $C U L$ may therefore be positive or negative depending on the relative strength of these competing factors. However, since the control industry, agriculture, forestry and fishing, is usually regarded as the industry most against the introduction of DST in Queensland, positive coefficients are expected.

The final set of information comprises dummy variables reflecting each respondent's regional location: namely, Sunshine Coast $(S U N)$, Gold Coast (GLD), Southwest Queensland $(S W E)$, Central Queensland $(C E N)$, Central Coast $(C N C)$, North Queensland $(N R Q)$ and Far North Queensland (FNQ). The control group for the regional dummy variables is Brisbane. As discussed, the debate on DST in Queensland has highlighted the divide between the more populous and urbanised south-eastern portion of the state (as represented by Brisbane and the Gold and Sunshine Coasts), which is generally in favour of DST, and rural and regional Queensland (corresponding to Southwest, Central, North and Far North Queensland and the Central Coast), which is mostly against. Being Australia's most decentralised and secondlongest state with two-thirds of its area lying in the tropics are further reasons why DST remains controversial in Queensland.

Since Brisbane is the control region, negative coefficients are hypothesised when support for the introduction of DST in Queensland as a whole $(D S Q)$ is regressed on SUN, GLD, $S W E, C E N, C N C, N R Q$ and $F N Q$. However, the directions of preferences regarding the 
introduction into the Brisbane and Gold Coast regions alone are less clear. Two competing hypotheses are likely. On one hand, rural and regional Queensland may regard the zonal adoption of DST in Brisbane or the Gold Coast as a means of reducing the political pressure for statewide DST. Positive coefficients are hypothesised. Alternatively, the zonal introduction of DST may be seen as merely pre-empting statewide DST: negative coefficients would be hypothesised.

\section{EMPIRICAL FINDINGS}

The estimated coefficients, standard errors and $p$-values of the parameters for the logit regressions are provided in Table 2. To facilitate comparability, marginal effects are also calculated. Also included in Table 2 are statistics for likelihood ratio (LR) tests and the Nagelkerke $R^{2}$. Six separate models are estimated. The estimated coefficients, standard errors, p-values and marginal effects employing the entire set of organisational, industry and regional characteristics as predictors for the support of DST in Queensland as a whole (DSQ) are shown in Table 2 columns 1 to 4 with a refined version in columns 5 to 8 . The results of estimations for the beginning and refined models predicting support for the introduction of DST in Brisbane alone (DSB) are detailed in columns 9 to 12 and 13 to 16 respectively. The models concerning the introduction of DST in the Gold Coast alone (DSG) are shown in columns 17 to 24 .

\section{<TABLE 2 HERE>}

The estimated models are all highly significant, with likelihood ratio tests of the hypotheses that all of the slope coefficients are zero rejected at the 1 percent level or lower using the chisquare statistic. To test for multicollinearity, variance inflation factors (VIF) are calculated. As a rule of thumb, a VIF greater than ten indicates the presence of harmful collinearity. Amongst the explanatory variables the highest VIFs are for $S A L$ (4.800), PRF (4.291), and $M N G$ (3.387). This suggests that multicollinearity, while present, is not too much of a problem. Somewhat atypically for cross-sectional data the $R^{2}$ of the first two regressions are fairly large, ranging from 0.648 to 0.664 , though those for the remaining four lie between 0.141 and 0.219 .

The models first discussed are those predicting support for the introduction of DST in Queensland as a whole ( $D S Q)$. In the beginning specification, the estimated coefficients for perceptions of the impact on staffing $(S T F)$, sales $(S A L)$ and administration and paperwork $(A D M)$ are significant at the 5 percent level of significance or lower and conform to a priori 
expectations. The estimated coefficients in the beginning specification also indicate that businesspersons in the electricity, gas, water and communications $(E W C)$ industry are more likely to support the introduction of DST (then when compared to the agriculture, forestry and fishing industry), while businesspersons in Southwest ( $S W E)$, Central $(C E N)$, North (NRQ) and Far North Queensland ( $F N Q$ ) are less likely to support its introduction (than compared to Brisbane). The three greatest marginal effects on the decision to support the introduction of DST are in the electricity, gas, water and communications (EWC) industry, which is associated with a six fold increase in the probability of supporting DST, and positive perceptions of the impact of DST on staffing $(S T F)$ and administration and paperwork $(A D M)$ where there is a 190 and 170 percent increase respectively in the probability of supporting DST in Queensland for a 10 percent increase in positive perceptions of DST on these factors.

These results are consistent with the estimated coefficients in the second refined regression, which is obtained by forward stepwise regression using a Wald criterion. Nine variables are stepped into the model ( $W$-statistics and $p$-values in brackets): $S T F$ (34.405, 0.000), $A D M$ (21.870, 0.000), FNQ (15.920, 0.000), SAL (14.605, 0.000), NRQ (8.174, 0.004), $S W E$ (7.999, 0.005), CON (7.103, 0.008), CEN (5.733, 0.017) and GLD (3.169, 0.075). The estimated coefficients for the staffing $(S T F)$, sales $(S A L)$, administration and paperwork $(A D M)$, Southwest Queensland $(S W E)$, Central Queensland $(C E N)$, North Queensland $(N R Q)$ and Far North Queensland $(F N Q)$ parameters found to be significant in the initial specification are also significant (at higher levels) in the refined model. In addition, in the second regression the estimated coefficients for the construction industry $(C O N)$ and the Gold Coast region (GLD) are significant at the 1 percent level of significance and the signs conform to a priori expectations. Overall, businesspersons with positive perceptions of DST on staffing, sales and administration and paperwork costs and who are located in the Gold Coast are more likely to support the introduction of DST in Queensland (then when compared to Brisbane), while those in the construction industry or located in Southwest, Central, North or Far North Queensland are less likely to support DST (when compared to the agriculture, forestry and fishing industry and Brisbane respectively).

The results in the third and fourth regressions in Table 3 are where the support for the introduction of DST in Brisbane alone is regressed against the same set of explanatory variables. Perceptions of favourable current business conditions (BST), the finance and insurance $(F I N)$ and cultural and recreational services $(C U L)$ industries, and the Southwest Queensland ( $S W E$ ), Central Queensland $(C E N)$, Central Coast $(C N C)$, North Queensland $(N R Q)$ and Far North Queensland $(F N Q)$ regions are significant at the .05 level or lower and 
the signs on these coefficients are consistent with a priori expectations. A refined model based on forward stepwise regression includes nine variables (excluding the constant) in the order of ( $W$-statistics and $p$-values in brackets): $\operatorname{STF}$ (13.510, 0.000), $S W E$ (12.938, 0.000), FNQ (9.722, 0.002), CNC (9.370, 0.002), NRQ (8.162, 0.004), CEN (7.995, 0.005), CUL (5.915, 0.015), BST (4.880, 0.027) and FIN (4.238, 0.040). Overall, businesspersons who have a more positive outlook on current business conditions and staffing, and in the finance and insurance or cultural and recreational services industries (as compared to agriculture, forestry and fishing) are more likely to support the introduction of DST into Brisbane alone, while those in located in Southwest, Central, Central Coast, North or Far North Queensland (as compared to Brisbane) are less likely to support its introduction on this basis. The greatest marginal effects on support for the introduction of DST into Brisbane alone are in the finance and insurance or cultural and recreational services industries.

The last eight columns in Table 3 are the estimated parameters supporting the introduction of DST in the Gold Coast alone. The results in the beginning model are directly comparable to the beginning model for the introduction of DST in Brisbane. However, in the refined model only seven variables (excluding the constant) are stepped in using the Wald criterion. These are ( $W$-statistic and $p$-value in brackets): $S W E$ (11.364, 0.001), $N R Q(9.985,0.002)$, CNC (9.034, 0.003), FNQ (8.674, 0.003), STF (7.063, 0.008), CEN (6.828, 0.009) and CUL (3.861, 0.049). The suggestion is that businesspersons with more positive perceptions of the impact of DST on staffing or in the cultural or recreational services industry are more likely to support the introduction of DST in the Gold Coast region alone, while businesses located in Southwest, Central, Central Coast, North or Far North Queensland (as compared to Brisbane) are less likely to support its introduction.

As a final requirement, the ability of the various models to accurately predict outcomes is examined. Table 3 provides the predicted results for each model specification and compares these to the probabilities obtained from a constant probability model. The probabilities in the constant probability model correspond to the probability of correctly identifying support for or against the introduction of DST on the basis of the proportion of support for or against DST in the sample. To start with, on the basis of the 426 respondents who support the introduction of DST in Queensland, the beginning model specification identifies 367 cases (86.2 percent) as supporters and 59 cases (13.8 percent) as non-supporters. Of the 282 respondents who did not support DST in Queensland, the beginning specification correctly identifies 226 (80.1 percent) as non-supporters and 56 (19.9 percent) as supporters. 


\section{$<$ TABLE 3 HERE $>$}

This means that the beginning specification correctly identifies 593 (83.8 percent) as either supporting or rejecting the introduction of DST in Queensland and incorrectly identifies 115 (16.2 percent) respondents as supporters or rejecters of DST. This is an absolute improvement of 61.1 percent over the constant probability model (in terms of correct predictions) and a relative improvement of 69.8 percent over the constant probability model (in terms of incorrect predictions). The refined model delivers a comparable level of correct and incorrect predictions regarding the introduction of DST in Queensland, albeit with a smaller number of estimated parameters. Of course, these are 'in-sample' predictions and the results could differ if 'out-of-sample' data was made available. The Hosmer-Lemeshow goodness-of-fit test statistics for the beginning and refined models $(H L=8.096, p$-value $=0.424$ and $H L=4.153$, $p$-value $=0.843$ ) in Table 4 both fail to reject the null hypotheses of no functional misspecification for the model of support for DST in Queensland.

At first impression, the prediction success of the models concerning the introduction of DST into the Brisbane and Gold Coast alone appears to offer relatively lower improvement in the percentage correct over the constant probability model. For example, the refined version of the Brisbane only model correctly identifies 74.9 percent of respondents while the constant probability model correctly identifies 61.6 percent. Likewise, in the Gold Coast only refined model the prediction success is 73.4 percent and 61.0 percent in the constant probability model. This would suggest that knowledge of the organisational, industry and regional characteristics of businesspersons in Queensland gives only marginal predictive accuracy in identifying supporters for the zonal introduction of DST. For instance, in the refined model for introducing DST in Brisbane alone 95.4 percent of respondents are predicted as nonsupporters of zonal DST and just 16.3 percent are correctly identified as supporters.

However, this still represents an absolute improvement (in terms of correct predictions) over the constant probability model of 11.4 percent and a relative improvement (in terms of incorrect predictions) of 61.8 percent. The Hosmer-Lemeshow goodness-of-fit test statistic for the beginning and refined models of support for DST in the Gold Coast only ( $H L=15.925, p$ value $=0.043$ and $H L=13.800, p$-value $=0.087)$ in Table 4 both accept and reject the null hypotheses of no functional misspecification at the .05 level, respectively. We may conclude that the organisational, industry and regional characteristics as specified in this analysis are somewhat better at predicting the supporters or non-supporters for DST in Queensland as a whole (83.8 percent) than for the lower level of support for DST in Brisbane alone (74.9 
percent), and in the Gold Coast alone (73.4 percent). One suggestion is that preferences for the introduction of DST into Brisbane and/or the Gold Coast may bear less relation to the business conditions specified than that modelling the introduction of DST into Queensland as a whole. For example, the variables specified take no account of Queensland businesses operating in a number of different regions (who would therefore not favour intrastate time differences), let alone the personal preferences of those sampled supporting DST regarding improvements in their own leisure.

\section{CONCLUDING REMARKS AND POLICY RECOMMENDATIONS}

The present study uses binary logit models to investigate the role of organisational, industry and regional characteristics in determining support for the introduction of daylight saving in Queensland. The current paper extends empirical work in this area in at least two ways. First, it represents the first attempt to apply qualitative statistical models to preferences and expectations concerning daylight saving in Australia. In fact no comparable study is thought to exist elsewhere in terms of the focus on the perceived business impact associated with the possible introduction of daylight saving. The evidence provided suggests that support for the introduction of daylight saving is very much a function of the potential impact of daylight saving on profits, sales, staffing and administration/paperwork costs in Queensland businesses and to a lesser extent on industry type and regional location. Second, the study analyses in detail different expectations and preferences as they relate to the policy of the statewide introduction of daylight saving as against an alternative policy of introducing daylight saving on a regional basis. A number of policy changes are suggested.

First, a primary driver of business support for daylight saving is shown to be expectations of increased profits and sales and lower administration/paperwork costs and staffing levels following its introduction. This suggests that daylight saving is not regarded as merely a nominal business adjustment, but is perceived to have the potential to exert a real influence on the functioning and performance of the Queensland economy. Unfortunately, the data gathered in this particular study is unable to shed light on whether the benefits to business following the possible introduction of daylight saving in Queensland would flow more from the time conformity with the practicing daylight saving states and territories of NSW, Victoria, Tasmania, South Australia and the ACT or from daylight saving per se. Second, the study has also shown that there is little business support for the introduction of daylight saving on a regional basis. That support which exists appears to bear little relation to the 
organisational, industry and regional characteristics found to be so useful in predicting the support for daylight saving on a statewide basis.

Third, even after taking into account the posited impact of daylight saving on business conditions, there are strong divisions between industries and regions supporting or rejecting the move to daylight saving in Queensland. All other things being equal, industries in favour of daylight saving in Queensland in one form or another include the finance and insurance, electricity, gas, water and communications and cultural and recreational services industries while opposition is drawn from the construction industry (as compared to agriculture, forestry and fishing). Putting aside organisational and industry characteristics, there is also a strong rural and regional bias against the introduction of daylight saving in most of Queensland with support largely restricted to the Gold Coast and Brisbane. This suggests that factors outside of potential business impacts may influence the preferences for and against the introduction of daylight saving. Possibilities may include longstanding cultural and social norms and the lower marginal benefit associated with summer daylight saving in the sub-tropical and tropical areas that cover much of the state.

Finally, there is little support for an alternative policy of introducing daylight saving into selected regions. While businesses with most of their operations concentrated in Brisbane and/or the Gold Coast may benefit from time harmonisation with the daylight saving states, those spread across a number of regions may find this outcome even more problematic than the present situation. While this could address the strong regional biases towards and against the adoption of daylight saving, such a policy change may also be regarded as an incremental move towards statewide DST and the lack of support may reflect such opposition. However, opposition may also exist for rather more prosaic reasons. For example, the fact that the state includes tropical, sub-tropical and temperate zones means that the marginal benefits of daylight saving (in terms of extra summer evening time) are significantly less in most of rural and regional Queensland. By itself, this may be enough to dissuade popular support for policy change.

There are, of course, a number of ways in which research into the economic impact of daylight saving could usefully be extended. Certainly, there is no known analysis quantifying the presumably significant increase in household utility from the daylight recreation and leisure time associated with daylight saving, in Australia, let alone Queensland. Nor has any research effort been directed at how the nominal change in daylight influences expenditure decisions by households. Combined together, a better understanding of the impact of daylight 
saving on households would complement this research and provide meaningful quantifiable input into this ongoing policy debate.

\section{REFERENCES}

AgForce Queensland. (1999), Zonal Daylight Saving May Create More Problems, $<$ http://www.agforceqld.org.au/>, Accessed April 2003.

AgForce Queensland. (2001) Daylight Saving Proposal Not an Option, <http://www.agforceqld.org.au/>, Accessed April 2003.

Coren, S. (1996a), “Accidental Death and the Shift to Daylight Savings Time”, Perception and Motor Skills, 83, 921-922.

Coren, S. (1996b), "Daylight Saving Time and Traffic Accidents”, New England Journal of Medicine, 334, 924.

Ferguson, S.A., Preusser, D.F., Lund, A.K., Zador, P.L. and Ulmer, R.G. (1995), "Daylight Saving Time and Motor Vehicle Crashes: The Reduction in Pedestrian and Vehicle Occupant Fatalities”, American Journal of Public Health, 85, 92-95.

Fortitude Valley and Districts Chamber of Commerce. (2003) Daylight Saving Time, <http://www.valleychamber.com.au/>, Accessed April 2003.

Green, H. (1980). "Some Effects on Accidents of Changes in Light Conditions at the Beginning and End of British Summer Time”, UK Transport and Road Research Laboratory, Supplementary Report No. 587.

Hicks, R.A., Lyndseth, K. and Hawkins, J. (1983), "Daylight Saving Time Changes Increase Traffic Accidents”, Perceptual and Motor Skills, 56, 64-66.

Kamstra, M.J., Kramer, L.A. and Levi, M.D. (2000), "Losing Sleep at the Market: The Daylight Saving Anomaly”, American Economic Review, 90, 1005-1011.

Kamstra, M.J. Kramer, L.A. and Levi, M.D. (2002), "Losing Sleep at the Market: The Daylight Saving Anomaly - Reply”, American Economic Review, 92, 1257-1263.

Lambe, M. and Cummings, P. (2000), "The Shift To and From Daylight Savings Time and Motor Vehicle Crashes”, Accident Analysis and Prevention, 32, 609-611.

Pinegar, J.M. (2002), “Losing Sleep at the Market: Comment”, American Economic Review, 92, 1251-1256.

Rock, B.A. (1997), “Impact of Daylight Saving Time on Residential Energy Consumption and Cost”, Energy and Buildings, 25, 63-68.

Shapiro, C.M., Blake, F., Fossey, A. and Adams, B. (1990), "Daylight Saving Time in Psychiatric Illness", Journal of Affective Disorders, 19, 177-181.

Sullivan, J.M. and Flannagan, M.J. (2002), "The Role of Ambient Light in Fatal Crashes: Inferences from Daylight Saving Time Transitions", Accident Analysis and Prevention, 34, 487-498.

Varughese, J. and Allen, R.P. (2001), "Fatal Accidents Following Changes in Daylight Savings Time: The American Experience”, Sleep Medicine, 2, 31-36.

Vincent, A. (1998), "Effects of Daylight Savings Time on Collision Rates”, New England Journal of Medicine, 339, 1167-1168.

Whittaker, J. (1996), “An Investigation into the Effects of British Summer Time on Road Traffic Accidents in Cheshire”, Journal of Accident and Emergency Medicine, 13, 189-192.

Worthington, A.C. (2003a), "Business Expectations and Preferences Regarding the Introduction of Daylight Saving in Queensland", Discussion Papers in Economics, Finance and International Competitiveness, School of Economics and Finance, Queensland University of Technology, No. 145.

Worthington, A.C. (2003b), "Losing Sleep at the Market: An Empirical Note on the Daylight Saving Anomaly in Australia”, Economic Papers, 22, 83-93. 
TABLE 1

VARIABLE DEFINITIONS AND DESCRIPTIVE STATISTICS

\begin{tabular}{|c|c|c|c|c|c|}
\hline Variable description & Code & Mean & Std. dev. & Skewness & Kurtosis \\
\hline \multicolumn{6}{|c|}{ Dependent variables } \\
\hline \multicolumn{6}{|l|}{ Opinions regarding the introduction of DST } \\
\hline Favour the introduction of DST in Queensland & DSQ & 0.602 & 0.490 & -0.416 & -1.832 \\
\hline Favour the introduction of DST in Brisbane alone & DSB & 0.260 & 0.439 & 1.097 & -0.798 \\
\hline Favour the introduction of DST in the Gold Coast alone & DSG & 0.266 & 0.442 & 1.064 & -0.870 \\
\hline \multicolumn{6}{|c|}{$\begin{array}{ll} & \text { Independent variables }\end{array}$} \\
\hline \multicolumn{6}{|l|}{ Organisational characteristics } \\
\hline Perceptions of current business conditions & BST & 3.332 & 1.039 & -0.674 & 1.151 \\
\hline Perceptions of future business conditions & BSF & 3.153 & 1.081 & -1.143 & 1.510 \\
\hline Perceived impact of DST on staffing & STF & 0.806 & 1.820 & -0.432 & 0.009 \\
\hline Perceived impact of DST on sales & SAL & 0.756 & 1.693 & -0.292 & 0.248 \\
\hline Perceived impact of DST on administration & ADM & 0.874 & 1.749 & -0.277 & 0.054 \\
\hline Perceived impact of DST on profits & PRF & 0.643 & 1.571 & -0.191 & 0.547 \\
\hline Number of employees in organisation & EMP & 85.651 & 446.960 & 12.082 & 163.564 \\
\hline \multicolumn{6}{|l|}{ Industry characteristics } \\
\hline Mining & MNG & 0.032 & 0.177 & 5.285 & 26.008 \\
\hline Manufacturing & MFG & 0.206 & 0.405 & 1.455 & 0.118 \\
\hline Electricity, gas, water and communications & ENG & 0.032 & 0.177 & 5.285 & 26.008 \\
\hline Construction & $\mathrm{CON}$ & 0.061 & 0.239 & 3.686 & 11.620 \\
\hline Wholesale trade & WTR & 0.082 & 0.274 & 3.055 & 7.356 \\
\hline Retail trade & RTR & 0.092 & 0.289 & 2.833 & 6.044 \\
\hline Accommodation, cafes and restaurants & ACR & 0.045 & 0.208 & 4.388 & 17.303 \\
\hline Transport & TRN & 0.062 & 0.242 & 3.635 & 11.245 \\
\hline Finance and insurance & FIN & 0.044 & 0.205 & 4.469 & 18.020 \\
\hline Property and business services & PRP & 0.081 & 0.272 & 3.090 & 7.570 \\
\hline Government services & GOV & 0.095 & 0.293 & 2.776 & 5.720 \\
\hline Cultural and recreational services & CUL & 0.090 & 0.287 & 2.863 & 6.214 \\
\hline \multicolumn{6}{|l|}{ Regional characteristics } \\
\hline Sunshine Coast & SUN & 0.034 & 0.181 & 5.162 & 24.718 \\
\hline Gold Coast & GLD & 0.145 & 0.353 & 2.015 & 2.067 \\
\hline Southwest Queensland & SWE & 0.109 & 0.312 & 2.519 & 4.356 \\
\hline Central Queensland & CEN & 0.068 & 0.252 & 3.446 & 9.901 \\
\hline Central Coast & CNC & 0.062 & 0.242 & 3.635 & 11.245 \\
\hline North Queensland & NRQ & 0.071 & 0.256 & 3.359 & 9.310 \\
\hline Far North Queensland & FNQ & 0.090 & 0.287 & 2.863 & 6.214 \\
\hline
\end{tabular}

Notes: (a) Dependent variables are binary variables (not in favour 0 , in favour 1) regarding the introduction of DST throughout Queensland (DSQ), in Brisbane region alone (DSB) and in Gold Coast region alone (DSG). (b) Independent variables for perceptions of current (BST) and future quarter (BSF) business conditions are derived from responses to the following statements: Very poor 1, poor 2, satisfactory 3, good 4, very satisfactory 5. (c) Independent variables for the perceived impact of DST on staffing (STF), sales (SAL), administration costs/paperwork (ADM) and profits (PRF) are derived from responses to the following statements: Very strong negative -4 , strong negative -3 , some negative -2 , little negative -1 , no influence 0 , little positive +1 , some positive +2 , strong positive +3 , very strong positive +4 . (d) The control for the industry dummy variables (MNG, MFG, ENG, CON, WTR, RTR, ACR, TRN, FIN, PRP. GOV, CUL) is agriculture, forestry and fishing. (e) The control for the regional dummy variables (SUN, GLD, SWE, CEN, CNC, NRQ, FNQ) is Brisbane. (f) The critical values for skewness and kurtosis are 0.092 and 0.184 , respectively. 
TABLE 2

ESTIMATED BINARY LOGIT MODELS

\begin{tabular}{|c|c|c|c|c|c|c|c|c|c|c|c|c|c|c|c|c|c|c|c|c|c|c|c|c|}
\hline \multirow[b]{3}{*}{ 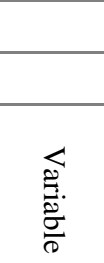 } & \multicolumn{8}{|c|}{ Introduction of DST in Queensland (DSQ) } & \multicolumn{8}{|c|}{ Introduction of DST in Brisbane (DSB) } & \multicolumn{8}{|c|}{ Introduction of DST in Gold Coast (DSG) } \\
\hline & \multicolumn{4}{|c|}{ Beginning model (i) } & \multicolumn{4}{|c|}{ Refined model (ii) } & \multicolumn{4}{|c|}{ Beginning model (iii) } & \multicolumn{4}{|c|}{ Refined model (iv) } & \multicolumn{4}{|c|}{ Beginning model (v) } & \multicolumn{4}{|c|}{ Refined model (vi) } \\
\hline & 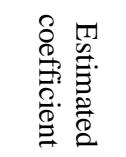 & 兽 & 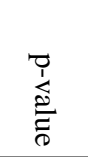 & 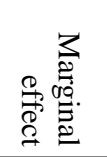 & 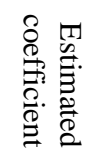 & 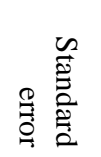 & 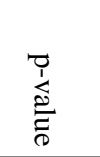 & 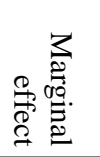 & 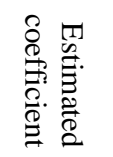 & 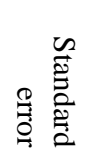 & 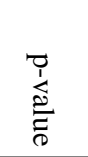 & 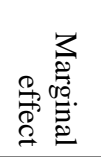 & 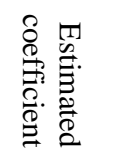 & 惫 & 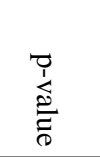 & 逽 & 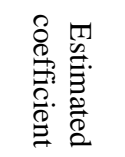 & 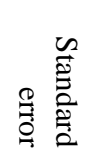 & 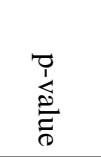 & 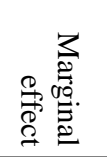 & 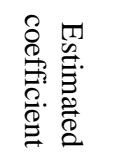 & 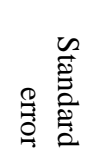 & 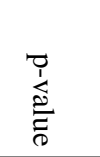 & 逽 \\
\hline CONS. & -0.447 & 0.627 & 0.476 & -0.639 & -0.255 & 0.174 & 0.142 & -0.775 & -2.052 & 0.581 & 0.000 & -0.129 & -1.666 & 0.355 & 0.000 & -0.189 & -1.601 & 0.528 & 0.002 & -0.202 & -0.809 & 0.132 & $0.000-$ & -0.445 \\
\hline BST & 0.060 & 0.138 & 0.663 & 1.062 & & & & & 0.261 & 0.113 & 0.020 & 1.298 & 0.209 & 0.094 & 0.027 & 1.232 & 0.212 & 0.109 & 0.051 & 1.236 & & & & \\
\hline BSF & -0.128 & 0.130 & 0.326 & -0.880 & & & & & -0.127 & 0.109 & 0.241 & -0.880 & & & & & -0.127 & 0.105 & 0.229 & -0.881 & & & & \\
\hline STF & 0.686 & 0.126 & 0.000 & 1.985 & 0.714 & 0.122 & 0.000 & 2.043 & 0.117 & 0.090 & 0.193 & 1.124 & 0.218 & 0.059 & 0.000 & 1.244 & 0.042 & 0.087 & 0.626 & 1.043 & 0.149 & 0.056 & 0.008 & 1.161 \\
\hline SAL & 0.378 & 0.167 & 0.024 & 1.459 & 0.487 & 0.127 & 0.000 & 1.627 & 0.045 & 0.119 & 0.707 & 1.046 & & & & & 0.007 & 0.116 & 0.949 & 1.007 & & & & \\
\hline $\mathrm{ADM}$ & 0.544 & 0.132 & 0.000 & 1.723 & 0.573 & 0.123 & 0.000 & 1.773 & 0.035 & 0.094 & 0.708 & 1.036 & & & & & 0.008 & 0.092 & 0.932 & 1.008 & & & & \\
\hline PRF & 0.280 & 0.190 & 0.141 & 1.323 & & & & & 0.056 & 0.122 & 0.642 & 1.058 & & & & & 0.118 & 0.119 & 0.321 & 1.125 & & & & \\
\hline EMP & 0.000 & 0.000 & 0.128 & 1.000 & & & & & 0.000 & 0.000 & 0.908 & 1.000 & & & & & 0.000 & 0.000 & 0.939 & 1.000 & & & & \\
\hline MNG & 0.150 & 0.823 & 0.856 & 1.162 & & & & & 0.739 & 0.782 & 0.345 & 2.095 & & & & & 0.796 & 0.704 & 0.259 & 2.216 & & & & \\
\hline MFG & 0.431 & 0.572 & 0.450 & 1.539 & & & & & 0.679 & 0.508 & 0.181 & 1.973 & & & & & 0.492 & 0.460 & 0.285 & 1.635 & & & & \\
\hline ENG & 1.834 & 0.874 & 0.036 & 6.261 & & & & & 0.530 & 0.687 & 0.441 & 1.698 & & & & & 0.099 & 0.671 & 0.883 & 1.104 & & & & \\
\hline $\mathrm{CON}$ & -0.673 & 0.661 & 0.308 & -0.510 & -1.176 & 0.441 & 0.008 & -0.309 & 0.078 & 0.636 & 0.903 & 1.081 & & & & & -0.162 & 0.594 & 0.785 & -0.850 & & & & \\
\hline WTR & 0.543 & 0.678 & 0.423 & 1.721 & & & & & 0.769 & 0.551 & 0.163 & 2.157 & & & & & 0.613 & 0.507 & 0.226 & 1.846 & & & & \\
\hline RTR & 0.333 & 0.633 & 0.599 & 1.395 & & & & & 0.182 & 0.655 & 0.781 & 1.199 & & & & & -0.156 & 0.612 & 0.799 & -0.856 & & & & \\
\hline ACR & 0.643 & 0.776 & 0.407 & 1.902 & & & & & 0.582 & 0.649 & 0.370 & 1.790 & & & & & 0.365 & 0.604 & 0.546 & 1.440 & & & & \\
\hline TRN & 0.867 & 0.727 & 0.233 & 2.380 & & & & & 0.530 & 0.603 & 0.379 & 1.699 & & & & & 0.491 & 0.552 & 0.373 & 1.634 & & & & \\
\hline FIN & 0.644 & 0.721 & 0.371 & 1.905 & & & & & 1.524 & 0.622 & 0.014 & 4.589 & 0.866 & 0.420 & 0.040 & 2.377 & 1.100 & 0.580 & 0.058 & 3.005 & & & & \\
\hline PRP & 0.000 & 0.645 & 1.000 & 1.000 & & & & & 0.784 & 0.563 & 0.164 & 2.190 & & & & & 0.664 & 0.516 & 0.199 & 1.942 & & & & \\
\hline GOV & 0.977 & 0.612 & 0.111 & 2.656 & & & & & 0.876 & 0.553 & 0.114 & 2.401 & & & & & 0.724 & 0.503 & 0.150 & 2.063 & & & & \\
\hline CUL & 0.740 & 0.622 & 0.234 & 2.096 & & & & & 1.368 & 0.551 & 0.013 & 3.926 & 0.760 & 0.312 & 0.015 & 2.137 & 1.090 & 0.503 & 0.030 & 2.975 & 0.591 & 0.301 & 0.049 & 1.806 \\
\hline SUN & -0.841 & 0.678 & 0.215 & -0.431 & & & & & -0.767 & 0.607 & 0.206 & -0.465 & & & & & -0.532 & 0.552 & 0.336 & -0.587 & & & & \\
\hline GLD & 0.608 & 0.386 & 0.115 & 1.836 & 0.630 & 0.354 & 0.075 & 1.878 & 0.099 & 0.252 & 0.695 & 1.104 & & & & & 0.135 & 0.250 & 0.588 & 1.145 & & & & \\
\hline SWE & -1.196 & 0.391 & 0.002 & -0.302 & -1.007 & 0.356 & 0.005 & -0.365 & -1.304 & 0.387 & 0.001 & -0.271 & -1.315 & 0.366 & 0.000 & -0.268 & -1.163 & 0.370 & 0.002 & -0.313 & -1.164 & 0.345 & $0.001-$ & -0.312 \\
\hline CEN & -1.194 & 0.517 & 0.021 & -0.303 & -1.134 & 0.474 & 0.017 & -0.322 & -1.310 & 0.564 & 0.020 & -0.270 & -1.535 & 0.543 & 0.005 & -0.215 & -0.942 & 0.483 & 0.051 & -0.390 & -1.193 & 0.456 & $0.009-$ & -0.303 \\
\hline CNC & -0.259 & 0.493 & 0.600 & -0.772 & & & & & -2.195 & 0.756 & 0.004 & -0.111 & -2.263 & 0.739 & 0.002 & -0.104 & -1.830 & 0.636 & 0.004 & -0.160 & -1.841 & 0.613 & $0.003-$ & -0.159 \\
\hline NRQ & -1.582 & 0.486 & 0.001 & -0.206 & -1.304 & 0.456 & 0.004 & -0.272 & -1.540 & 0.552 & 0.005 & -0.214 & -1.543 & 0.540 & 0.004 & -0.214 & -1.610 & 0.550 & 0.003 & -0.200 & -1.699 & 0.538 & $0.002-$ & -0.183 \\
\hline FNQ & -1.934 & 0.451 & 0.000 & -0.145 & -1.601 & 0.406 & 0.000 & -0.202 & -1.310 & 0.438 & 0.003 & -0.270 & -1.287 & 0.413 & 0.002 & -0.276 & -1.191 & 0.417 & 0.004 & -0.304 & -1.142 & 0.388 & $0.003-$ & -0.319 \\
\hline LR(p) & 473.707 & & 0.000 & & 490.369 & & 0.000 & & 696.887 & & 0.000 & & 708.878 & & 0.000 & & 729.079 & & 0.000 & & 747.641 & & 0.000 & \\
\hline $\mathrm{R}^{2}$ & 0.664 & & & & 0.648 & & & & 0.219 & & & & 0.197 & & & & 0.175 & & & & 0.141 & & & \\
\hline
\end{tabular}

Notes: (a) The dependent variable in models (i) and (ii) is DSQ, DSB in models (iii) and (iv) and DSG in (v) and (vi). (b) The beginning models in (i), (iii) and (v) are obtained by including all the independent variables in Table 1; the refined models in (iii), (iv) and (vi) are obtained by using forward stepwise regression using the Wald criterion. (c) $L R$ - likelihood ratio statistic; $p$-value of $L R$ calculated using $\chi^{2}(\mathrm{p})$ where $p=$ number of explanatory variables; $R^{2}-$ Nagelkerke R-squared; marginal effects calculated at sample means. 
TABLE 3

OBSERVED AND PREDICTED VALUES FOR THE BINARY LOGIT MODELS

\begin{tabular}{|c|c|c|c|c|c|c|c|c|c|c|}
\hline \multirow[t]{2}{*}{ Model } & \multirow[t]{2}{*}{ Outcomes } & & \multicolumn{2}{|c|}{$\begin{array}{l}\text { Observed in } \\
\text { sample }\end{array}$} & \multicolumn{2}{|c|}{$\begin{array}{c}\text { Constant } \\
\text { probability } \\
\text { model }\end{array}$} & \multicolumn{2}{|c|}{$\begin{array}{l}\text { Beginning } \\
\text { model }\end{array}$} & \multicolumn{2}{|c|}{$\begin{array}{c}\text { Refined } \\
\text { model }\end{array}$} \\
\hline & & & No & Yes & No & Yes & No & Yes & No & Yes \\
\hline \multirow{5}{*}{ 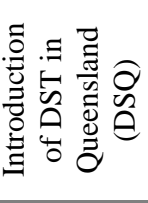 } & Prediction & No & 282 & 0 & 112 & 210 & 226 & 56 & 228 & 54 \\
\hline & Prediction & Yes & 0 & 426 & 170 & 256 & 59 & 367 & 61 & 365 \\
\hline & Percent correct & & 100.0 & 100.0 & 39.7 & 60.1 & 80.1 & 86.2 & 80.9 & 85.7 \\
\hline & Overall percent correct & & & 100.0 & & 52.0 & & 83.8 & & 83.8 \\
\hline & H-L statistic and p-value & & NA & NA & NA & NA & 8.096 & 0.424 & 4.153 & 0.843 \\
\hline \multirow{5}{*}{ 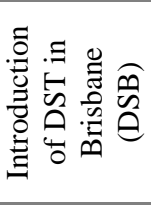 } & Prediction & No & 524 & 0 & 388 & 136 & 498 & 26 & 500 & 24 \\
\hline & Prediction & Yes & 0 & 184 & 136 & 48 & 153 & 31 & 154 & 30 \\
\hline & Percent correct & & 100.0 & 100.0 & 74.0 & 26.0 & 95.0 & 16.8 & 95.4 & 16.3 \\
\hline & Overall percent correct & & & 100.0 & & 61.6 & & 74.7 & & 74.9 \\
\hline & H-L statistic and p-value & & NA & NA & NA & NA & 8.019 & 0.432 & 10.476 & 0.233 \\
\hline \multirow{5}{*}{ 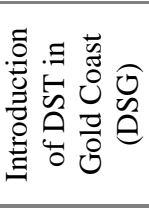 } & Prediction & No & 520 & 0 & 382 & 138 & 505 & 15 & 513 & 1 \\
\hline & Prediction & Yes & 0 & 188 & 138 & 50 & 162 & 26 & 181 & 7 \\
\hline & Percent correct & & 100.0 & 100.0 & 73.4 & 26.6 & 97.1 & 13.8 & 98.7 & 3.7 \\
\hline & Overall percent correct & & & 100.0 & & 61.0 & & 75.0 & & 73.4 \\
\hline & H-L statistic and p-value & & NA & NA & NA & NA & 15.925 & 0.043 & 13.800 & 0.087 \\
\hline
\end{tabular}

Notes: (a) Observed is the number of 0 (No) and 1 (Yes) responses in the sample; the probabilities in the constant probability model are the values computed from estimating a model that includes only an intercept term, and thereby corresponds to the probability of correctly identifying 0 and 1 responses on the basis of their proportion the sample; the beginning model is obtained by including all variables as specified and corresponds to the results obtained in models (i), (iii) and (v) in Table 2; the refined model is obtained by using forward stepwise regression using the Wald criterion and corresponds to the results obtained in models (ii), (iv) and (vi) in Table 2. (b) H-L Hosmer-Lemeshow test statistic; NA - not applicable. (c) Percent correct is the number of correct predictions for each model and for each response (i.e. 0 or 1 ) as a percentage of the observed values for 0 and 1 ; overall percent correct is the number of correct predictions (i.e. 0 and 1 ) as a percentage of the total observed values for 0 and 1. 